\title{
Heparanase: A Key Enzyme in Invasion and Metastasis of Gastric Carcinoma
}

Weihua Tang, M.D., Yasushi Nakamura, M.D., Ph.D., Masahiko Tsujimoto, M.D., Ph.D., Misako Sato, M.T., Xiaojuan Wang, M.D., Kazushi Kurozumi, M.D., Ph.D., Masaaki Nakahara, M.D., Kazuyasu Nakao, M.D., Misa Nakamura, Ph.D., Ichiro Mori, M.D., Ph.D., Kennichi Kakudo, M.D., Ph.D. Department of Pathology (WT, YN, MS, XW, MiN, IM, KeK), Wakayama Medical University, Wakayama, Japan; and Departments of Pathology (MT) and Surgery (KaK, MaN, KN), Osaka Police Hospital, Osaka, Japan

Previous reports have shown that the biochemical activity of heparanase is significantly correlated with the invasion and metastasis of malignant cells in vitro. Recently, it was found that the human heparanase gene was cloned and highly expressed in malignant cell lines and human solid malignant tumors. In the present study, we investigated the heparanase mRNA expression by using in situ hybridization in 116 paraffin-embedded tissues of primary gastric carcinomas. To explore its clinicopathologic significance, it was detected in the various steps of tumor progression and then compared with prognostic indicators. As a result, the heparanase expression was more prevalent in late-stage rather than early-stage carcinomas $(P<.0001)$ and was more frequent in tumors of large size $(P=.0212)$. Expression also correlated with lymphatic $(P=$ .0086) and venous $(P=.0171)$ invasion and with negative prognostic factors such as lymph nodal ( $P$ $<.0001)$ and distant $(P=.0221)$ metastases. However, in a multivariate analysis, messenger RNA expression of heparanase was not an independent prognostic factor. It was concluded that heparanase might play an important role in the development of invasion and metastasis of the gastric cancer. It was indicated that patients with heparanase-positive gastric carcinoma would have a greater chance of metastasis with a poor prognosis.

KEY WORDS: Extracellular matrix, Gastric cancer, Heparanase, Invasion, Metastasis, mRNA expression, Prognostic indicator.

Mod Pathol 2002;15(6):593-598

Copyright $\odot 2002$ by The United States and Canadian Academy of Pathology, Inc.

VOL. 15, NO. 6, P. 593, 2002 Printed in the U.S.A.

Date of acceptance: February 18, 2002.

Address reprint requests to: Kennichi Kakudo, Department of Pathology, Wakayama Medical University, 811-1 Kimiidera, Wakayama City, Wakayama, 641-8509 Japan; e-mail: kakudo-k@mail.wakayama-med. ac.jp; fax: 81-73-446-4825.
One of the characteristics of malignant cells is metastasis, whereby cancer cells invade parenchymal tissue and penetrate vascular channels to form satellite tumors in distant organs. In this process, the basement membrane (BM) and extracellular matrix (ECM) play a barrier to prevent tumor cells from invasion and metastasis $(1,2)$. The previous reports have shown that heparanase, produced by malignant tumor cells, can mediate the degradation of heparan sulfate proteoglycans (HSPGs) in ECM and BM (3-5) and is one of the key enzymes involved in the invasion and metastasis of malignant tumors (6-8). In addition, the cleavage of HSPGs by heparanase also may release heparan-sulfatebound cytokines and growth factors from cell surface or from the ECM, such as basic fibroblast growth factor. The a activăted growth factors induce angiogenesis, which is able to facilitate the growth and progression of tumors $(9,10)$. It was found that the human heparanase gene was cloned and its transfectants showed an increased heparanase activity and high metastatic potential (11-14). In the present study, we applied heparanase cRNA probes to investigate heparanase message expression at various stages of human gastric carcinoma to combine the expression with prognostic factors and explore its clinicopathological significance.

\section{MATERIALS AND METHODS}

One hundred and sixteen cases of primary gastric carcinomas were analyzed. Their histopathological specimens and clinicopathologic data were obtained from Osaka Police Hospital. The cases were randomly selected out of the database in the period from 1988 to 1998 and are summarized in Table 1. All the patients were followed up; the mean follow-up time was 35 months and ranged from 3 to 122 months. By the date of last contact, all cases except two had been followed for more than 12 months. Histological type and lymphatic and venous invasions of the tumors were evaluated ac- 


\begin{tabular}{|c|c|c|c|c|}
\hline Heparanase Expression $^{1}$ & Total & Positive (\%) & Negative (\%) & P Value $^{2}$ \\
\hline \multicolumn{5}{|l|}{ Sex of patients } \\
\hline $\mathrm{F}$ & 33 & $28(84.8)$ & $5(15.2)$ & \multirow[t]{2}{*}{0.7917} \\
\hline M & 83 & 68 (81.9) & $15(18.1)$ & \\
\hline \multicolumn{5}{|l|}{ Tumor size $^{3}(\mathrm{~cm})$} \\
\hline$<5$ & 49 & 36 (73.5) & $13(26.5)$ & \multirow[t]{2}{*}{0.0212} \\
\hline$\geq 5$ & 54 & $49(90.7)$ & $5(9.3)$ & \\
\hline \multicolumn{5}{|l|}{ Depth of invasion } \\
\hline Within $\mathrm{mp}^{4}$ & 41 & $28(68.3)$ & $13(31.7)$ & \multirow[t]{2}{*}{0.0029} \\
\hline Beyond mp & 75 & 68 (90.7) & 7 (9.3) & \\
\hline \multicolumn{5}{|l|}{ Lymphatic invasion } \\
\hline Negative & 56 & $41(73.2)$ & $15(26.8)$ & \multirow[t]{2}{*}{0.0086} \\
\hline Positive & 60 & 55 (91.7) & $5(8.3)$ & \\
\hline \multicolumn{5}{|l|}{ Nodal metastasis } \\
\hline Negative & 38 & $22(57.9)$ & $16(42.1)$ & \multirow[t]{2}{*}{$<0.0001$} \\
\hline Positive & 78 & 74 (94.9) & $4(5.1)$ & \\
\hline \multicolumn{5}{|l|}{ Venous invasion } \\
\hline Negative & 78 & $60(76.9)$ & $18(23.1)$ & \multirow[t]{2}{*}{0.0171} \\
\hline Positive & 38 & $36(94.7)$ & $2(5.3)$ & \\
\hline \multicolumn{5}{|l|}{ Distant metastasis ${ }^{5}$} \\
\hline Negative & 75 & $58(77.3)$ & $17(22.7)$ & \multirow[t]{2}{*}{0.0221} \\
\hline Positive & 37 & $35(94.6)$ & $2(5.4)$ & \\
\hline \multicolumn{5}{|l|}{ Stage $^{6}$} \\
\hline 0-IA & 13 & $4(30.8)$ & $9(69.2)$ & \multirow[t]{4}{*}{$<0.0001$} \\
\hline IB & 18 & $14(77.8)$ & $4(22.2)$ & \\
\hline II & 36 & $31(86.1)$ & $5(13.9)$ & \\
\hline III-IV & 49 & $47(95.9)$ & $2(4.1)$ & \\
\hline
\end{tabular}

${ }^{1}$ Negative indicates that no heparanase mRNA expression was identified with in situ hybridization; Positive: heparanase messenger RNA was positively labeled in tumor cells.

${ }^{2} \mathrm{P}$ values were obtained by using the chi-square test (negative vs. positive)

${ }^{3}$ No clinical data were found in 13 patients' files.

${ }^{4} \mathrm{mp}$ : proper muscle. files.

${ }^{5} 37$ of 116 patients were found to have liver and/or lung metastasis at the time of operation and/or recurrence, and there was no record in 4 patients'

${ }^{6}$ Stage grouping refers to TNM classification (UICC) 5th Edition, 1997 Stomach (ICD-O C16).

cording to the criteria of Japanese Classification of Gastric Carcinoma (15). Histological stage grouping, referred to as UICC TNM classification, was confirmed by histological examination.

\section{Preparation of Riboprobes (cRNA)}

Riboprobes (cRNA probes) of 254 bases (bases 296-559 of the total cDNA sequence [16], where no cross homologies were found in GeneBank database) were synthesized using an in vitro transcription carried out according to the manufacturer's instructions (MAXIscript ${ }^{\mathrm{TM}}$, Ambion Inc., Austin, TX). Briefly, the total cellular RNA was isolated from homogenization of $100 \mathrm{mg}$ fresh human placental tissue using a TRIzol ${ }^{\mathrm{TM}}$ RNA extraction kit (Invitrogen Corp., Carlsbad, CA). First-strand cDNA synthesis was produced from $5 \mu \mathrm{g}$ of total RNA using ThermoScript RT-PCR system (Invitrogen Corp.) and followed by a polymerase chain reaction (PCR) in the presence of primers containing the phage $\mathrm{T} 7$ or SP6 promoter sequence. Phage T7 promoter sequence (5'-TAATACGACTCACTATAGGGAGA) was added to antisense primer (5'-CCGTAACTTCTCCTCCACATC) and SP6 promoter (5'-ATTTAGGTGACACTATAGAAGA) to sense primers (5'-CCCTCGTTCCTGTCCGTCACC). Proofreading Taq DNA polymerase (Invitrogen Corp.) was used in the RT-
PCR. Taking the products of the PCR as templates, an in vitro transcription of antisense or sense (control) CRNA probes was carried out using T7 and SP6 RNA polymerase, respectively. The cRNA probes were labeled with Fluorescein-12-UTP (ChromaTide $^{\text {TM }}$ Molecular Probes, Eugene, OR).

\section{In Situ Hybridization}

In situ hybridization was performed as the previous description with a minor modification $(17,18)$. In brief, sections $5 \mu \mathrm{m}$ thick for in situ hybridization were prepared from paraffin tissue blocks. They were deparaffinized, dehydrated, and then digested in $0.05 \%$ pepsin $/ 0.2 \mathrm{~N}$ HCI for 30 minutes at $37^{\circ} \mathrm{C}$ and underwent acetylation. The slides were hybridized with $30 \mathrm{ng} / \mathrm{mL}$ FITC-labeled probes (sense and anti-sense) at $45^{\circ} \mathrm{C}$ overnight. Then the hybridized probes were stringently washed, detected by using AP-labeled anti-FITC rabbit $\mathrm{F}(\mathrm{ab})_{2}{ }_{2}$ (DAKO, Carpinteria, CA), and developed in BCIP/ NBT (DAKO).

Lymphocytes and endothelial cells were referred as internal positive control. In hybridization solution replaced cRNA probes as negative control. When lymphocytes were positive, blue staining of tumor cytoplasm, but not of nucleus, was judged as positive, regardless of number or arrangement of 
stained cells. The hybridized specimens were evaluated by three pathologists (W. Tang, Y. Nakamura, and M. Tsujimoto) independently. Only cases with positive lymphocytes and capillary endothelium in the mucosa, tumor stroma, or muscle layer were included in this study. Cases with negative staining of those cells were regarded as poorly fixed samples or as being inadequate for RNA evaluation and were not included in this study.

\section{Statistical Analysis}

Time-independent categorical data were evaluated using the $\chi^{2}$ test. Survival analysis was done with StatView-J 5.0 statistical software packages (SAS Institute, Inc., Cary, NC). For univariate analysis of time-dependent variables, the Kaplan-Meier method and the log rank test were used to determine significant prognostic factors. In multivariate analysis, a Cox proportional hazards regression model was used for all factors found to be significant in univariate analysis. The differences observed were assumed to be statistically significant if the probability of occurrence chance was less than 0.05 .

\section{RESULTS}

\section{Heparanase Expression in the Gastric Carcinomas}

Specimens of 116 cases of gastric carcinomas demonstrated staining of lymphocytes, endothelial cells, and occasionally fibroblasts in normal or carcinomatous stroma, when hybridized with antisense probes, and no signal was seen with sense probes. Among them, 101 cases had normal gastric mucosa adjacent to the neoplasm. No positive labeling of heparanase RNA was identified in normal foveolar epithelium of all the 101 cases, although mild staining was observed in the parietal cells of fundic glands in 26 cases and metaplastic glands in 15 cases. Of the 116 gastric carcinomas, 96 (83\%) cases showed positive labeling of heparanase RNA in carcinoma cells (Fig. 1A, B), and negative labeling was seen in the other $20(17 \%)$. No positive signal was identified in all cases when using sense RNA probes (Figure 1C). These positive cells were diffusely arranged in the carcinoma tissue with foci of deeper stained cells, especially in the invasive front or in the periphery of cancer cell nests (Fig. 2A). Cancer cell thrombi were positively labeled in lymphatic vessels or blood vessels (Fig. 2B). Heparanase mRNA was present in various differentiated adenocarcinomas, either well or poorly, and no conclusive correlation was identified between the heparanase and histological subtypes (data not shown).

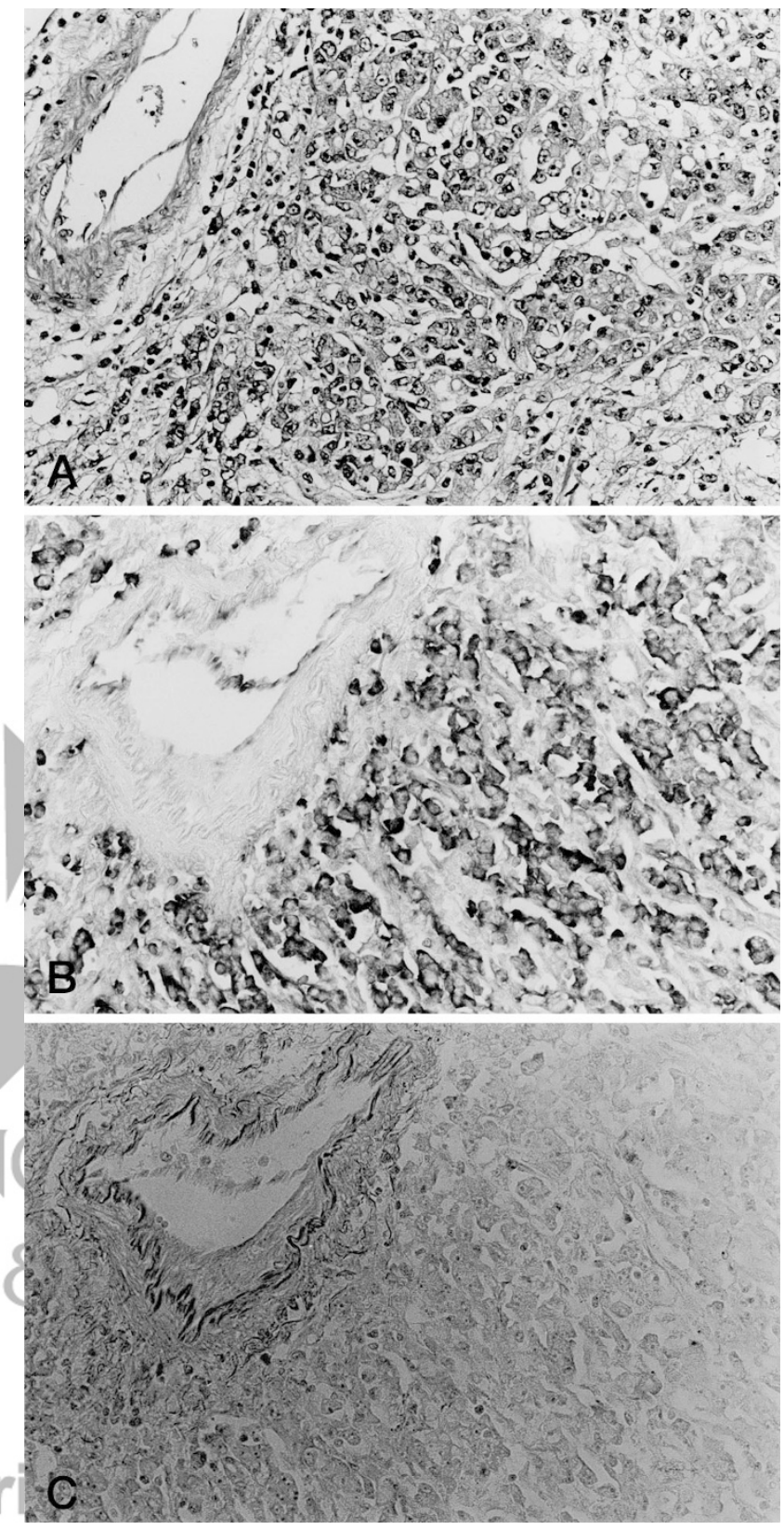

FIGURE 1. Heparanase mRNA expression (in situ hybridization, ISH) in gastric carcinoma. (A) A poorly differentiated carcinoma invaded in to subserosa (HE, $\times 200$ ). (B) Heparanase mRNA was positively labeled by antisense probes in the cytoplasm of neoplastic cells and endothelial cells of a blood vessel (left upper) (ISH, $\times 200)$. (C) When using sense probe, no positive signal was observed in the tumor (ISH, $\times 200$ ).

\section{Heparanase and Stage of Tumor}

The heparanase message was prevalently expressed in the advanced stage (III-IV) gastric carcinoma as shown in Table 1 (47/49 cases, 95.9\%). In the 116 cases, there were 13 cases of stage 0 -IA carcinomas, including 10 cases limited in the mucosa; three cases invaded into submucosa without lymph node metastasis. Two mucosal and two submucosal carcinomas demonstrated positive heparanase mRNA in their cytoplasm, but no heparanase message was detected in the other nine 


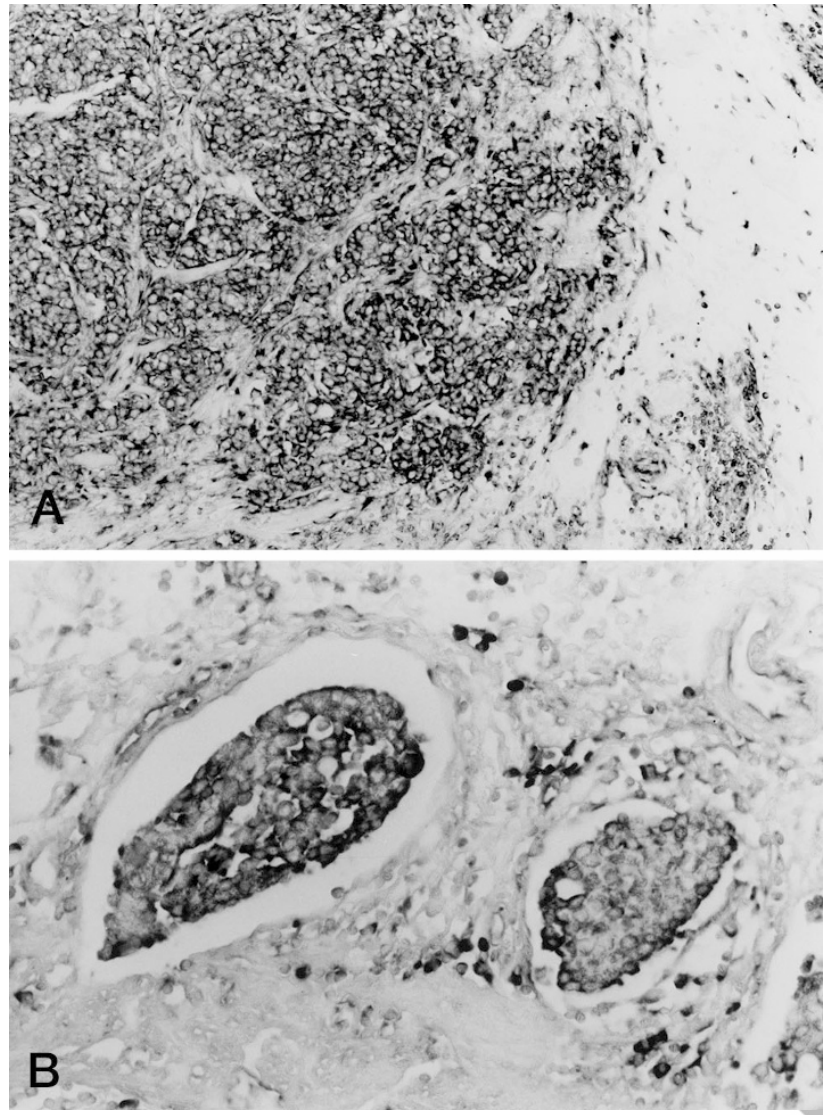

FIGURE 2. (A) Cancer cells demonstrate a diffusely positive arrangement and deeply staining is observed in the invasive front of tumor (ISH, $\times 100$ ). (B) Heparanase mRNA is positively expressed in cancer cell thrombi within vascular cannels $($ ISH $\times 200)$.

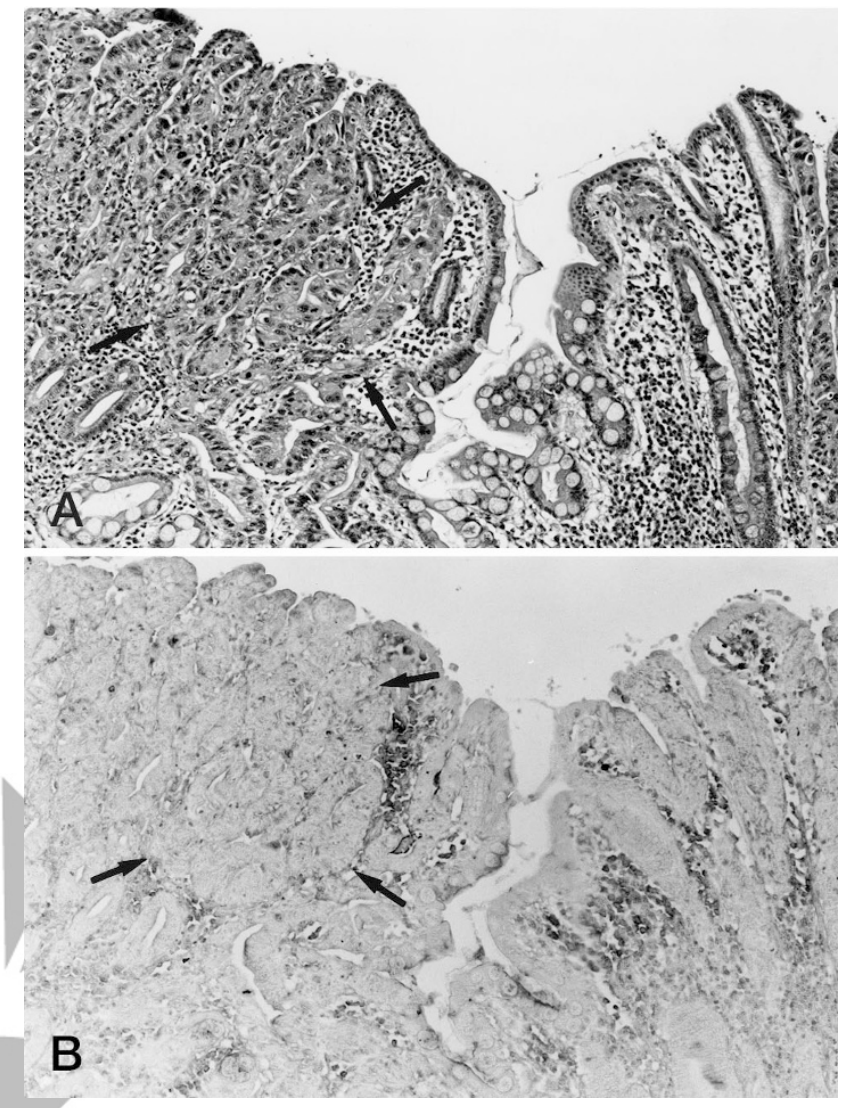

FIGURE 3. (A) Malignant cells (arrow) localized within the gastric mucosa in an early gastric carcinoma (HE, $\times 200)$. (B) In the same case, no labeled messenger RNA of heparanase was demonstrated in the malignant cells (arrow) even with antisense probes (ISH, $\times 200$ ). cases, including one submucosal carcinoma/and
eight noninvasive carcinomas (Fig. 3A, B). These results suggest lower heparanase mRNA expression in the early cancers $(4 / 13,30.8 \%)$ when compared with the other invasive cancers $(92 / 103,89.3 \%, P<$ $.0001)$. When the 116 cases were divided into two groups in accordance with the depth of invasion, the carcinomas beyond the proper muscle $(68 / 75$, $90.7 \%)$ demonstrated more frequent heparanase message expression than carcinomas limited within the proper muscle $(28 / 41,68.3 \%, P=.0029)$, including mucosa, submucosa, and into muscle layer. Furthermore, the tumors $5 \mathrm{~cm}$ in diameter or more expressed it more frequently than the tumors smaller than $5 \mathrm{~cm}(P=.0212)$.

\section{Heparanase and Venous or Lymphatic Invasion}

The 116 cases were classified into negative and positive groups, depending on venous or lymphatic invasion, as described in the Materials and Methods section. As shown in Table 1, heparanase message expression was more frequently found in the carcinomas with venous invasion (36/38 cases, $94.7 \%)$ than in those without venous invasion (60/78 cases $76.9 \%, P=.0171$ ); heparanase-positive cases also showed more frequent lymphatic invasion $(55 / 60,91.7 \%)$ than heparanase-negative tumors $(P=.0086)$. The lymphatic and venous involvements were associated with the distant metastasis and nodal metastasis, respectively (data not shown).

\section{Heparanase Expression with Lymph Node and Distant Metastasis}

Heparanase expression was evaluated in primary tumors but not in metastatic lesions. The cases with lymph node metastasis were more significantly observed in the heparanase mRNA-positive group $(74 / 78,94.9 \%)$ than in the negative group $(P<$ $.0001)$. The hematogenous metastasis was more frequently observed in cancers with positive heparanase staining $(35 / 37,74.6 \%, P=.0221)$.

\section{Heparanase Expression and Patient's Survival}

Heparanase expression, venous invasion, depth of invasion, lymph node metastasis, liver metastasis, and TNM stage were statistically correlated with the patients' survival by univariate analysis (Table 2 ). The overall 5-year survival rate of patients was 
TABLE 2. Heparanase Expression and Other Prognostic Predictors for Patients of Gastric Carcinoma by Univariate and Multivariate Analysis

\begin{tabular}{lcc}
\hline \multicolumn{1}{c}{ Variables } & $\begin{array}{c}\text { P Value }^{1} \\
\text { (univariate) }\end{array}$ & $\begin{array}{c}\text { P Value } \\
\text { (multivariate) }\end{array}$ \\
\hline Sex & 0.1066 & - \\
Heparanase & 0.0305 & 0.2030 \\
Size of tumor $(\mathrm{cm})$ & 0.0094 & 0.0920 \\
Depth of invasion & & 0.0007 \\
Lymphatic invasion & 0.0008 & - \\
Venous invasion & 0.1344 & 0.0319 \\
Lymph node metastasis & 0.0109 & 0.0417 \\
Distant metastasis & 0.0040 & $<0.0001$ \\
TNM stage & $<0.0001$ & 0.0096 \\
\hline
\end{tabular}

${ }^{1}$ In univariate analysis, the Kaplan-Meier method was used, and the $\mathrm{P}$ value was obtained by the log-rank test. A statistically significant result was defined as a $\mathrm{P}$ value of $<0.05$.

${ }^{2}$ Cox proportional hazard regression model was used in multivariate analysis, and $P$ value was obtained by log rank test.

${ }^{3}$ Carcinomas were divided into two groups, within proper muscle and beyond it.

$72.0 \%$ in the negative group but was $45.4 \%$ in the positive group. The patients with heparanasepositive carcinomas demonstrated significantly poorer survival $(P=.0305)$ than those with negative carcinomas (Fig. 4). However, in a multivariate analysis, messenger RNA expression of heparanase was not an independent prognostic factor. Depth of invasion, venous invasion, lymph nodal, and distant metastasis remained independent predictors of patient survival.

\section{DISCUSSION}

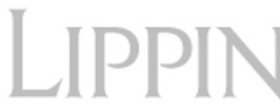

This study detected heparanase mRNA in a large series of gastric carcinomas and demonstrated that
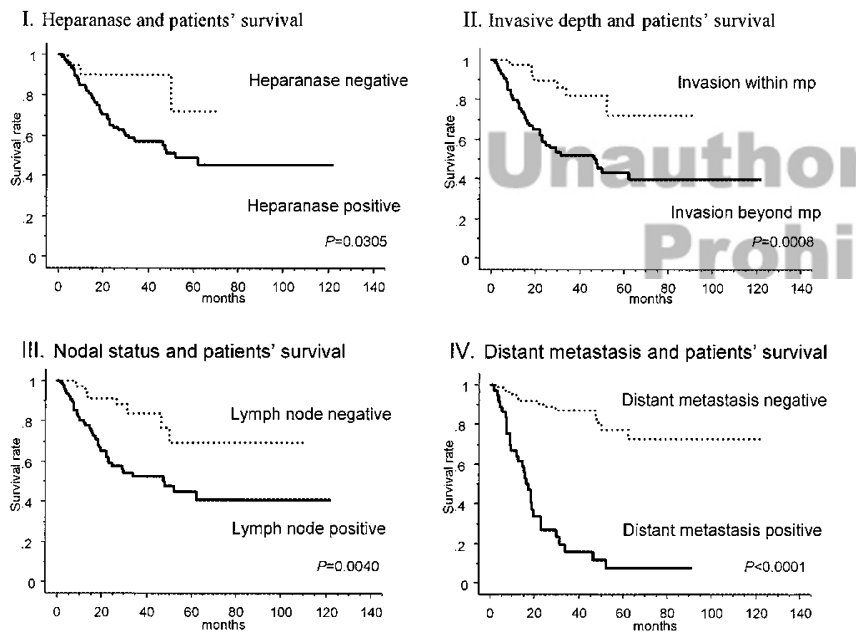

FIGURE 4. Kaplan-Meier survival curve for patients with gastric carcinomas $(n=116)$. (I) Overall 5-year survival rate of the patients with heparanase-positive carcinomas was significantly poorer than that of negative group (66.8\% versus $37.5 \% ; P=.0072$ ). (II) Five-year survival rate of patients with a cancer invading beyond proper muscle layer was $39.6 \%$, which was significantly different from those within the muscle layer $(71.8 \%, P=.0008)$. (III) Five-year survival rates in nodal positive and negative group were $40.8 \%$ and $69.2 \%$, respectively. (IV) Five-year survival rates: $7.7 \%$ in distant metastasis group and $77.6 \%$ in nonmetastasis group, $P<.0001$ the expression of heparanase message was frequently observed in advanced gastric cancers. The frequency was significantly correlated with histopathological parameters reflecting invasive and metastatic potentials and prognosis of gastric cancers.

Previous studies showed that heparanase is capable of degrading the heparan sulfate chains of HSPGs widely ranged in BM and ECM and enhancing the invasion and metastasis of malignant cells $(4,5,8,19,20)$. In this study, we have observed heparanase message expression even in very early invasive carcinomas within the lamina propria of gastric mucosa, but not in the normal epithelium or noninvasive carcinomas. Furthermore, heparanase message is frequently expressed in deeply invasive cancers and those in late stage. These factors imply that heparanase may play an important role in disrupting and penetrating the BM under epithelium by cancer cells. In the study reported by Friedmann and his coworkers, heparanase mRNA being consistent with its protein expression was found in hyperplastic polyps, adenomas, or invasive colon cancers (16). However, our results prefer to emphasize that the heparanase as a key enzyme is involved in an invasive progression of malignant tumors instead of in tumorigenesis, as we have concluded.

In experimental models, the cells expressing heparanase had a high potential for extravasation of tumor cells in vascular vessels and were susceptible to develop a lung metastasis $(21,22)$. Our findings further proved that the heparanase was involved not only in extravasation but also in entering in lymphatic or venous channels by cancer cells through rupturing BM and ECM around the vessels and then developing a metastasis (23). In addition, the cleavage of HSPGs by heparanase may regulate intratumor angiogenesis by releasing heparan-sulfate-bound cytokines and growth factors such as basic fibroblast growth factor $(9,10$, 24). Increased lymphatic and venous invasion is possible evidence of tumor angiogenesis. Many reports have shown that the presence of lymphatic and/or venous invasion is a strong risk factor for nodal metastasis, distant metastasis, and tumor recurrence in gastric cancer $(25,26)$.

Either as described in the previous studies or in our multivariate survival analysis, the depth of invasion, lymph node or distant metastasis, and TNM staging are independent prognostic indicators in gastric cancers $(25,26)$. The heparanase mRNA expression had a statistical correlation with those indicators. These may imply that invasive and metastatic activities promoted by heparanase induce a poor outcome in patients with gastric cancer.

In a recent article, it is said that RT-PCR did not correlate heparanase mRNA expression with clini- 
copathologic factors in gastric cancers (27). Although the RT-PCR gave quantitative results of heparanase mRNA, it was highly sensitive and its results were easily interfered with by heparanase mRNA that widely existed in stromal and inflammatory cells, as described in our study and in other previous reports (11-14). Our results were established on an observation of intact cells in situ, and we therefore found significant correlations between heparanase mRNA in cancer cells with clinicopathologic factors of gastric cancer. However, heparanase is not the only factor involved in the invasive process and it may also cooperate with others, such as matrix metalloproteinase (MMP) and plasminogen activators (PA) in tumor progression (28). Further studies are needed to explore heparanase mRNA in comparison with its protein expression in many physiological and pathological conditions.

Acknowledgment: In the period of this research, Dr. Weihua Tang obtained the Foreigner's research grant from Wakayama foundation for the Promotion of Medicine (scholarships awarded by NORITSUKOKI, CO., LTD).

\section{REFERENCES}

1. Poste G, Fidler I. The pathogenesis of cancer metastasis. Nature 1980;283:139-46.

2. Boyd D. Invasion and metastasis. Cancer Metastasis $\bar{R}$ ev 1996;15:77-89.

3. Kramer RH, Vogel KG, Nicolson GL. Solubilization and degradation of sub-endothelial-matrix glycoproteins and proteoglycans by metastatic tumor cells. J Biol Chem 1982;257: 2678-86.

4. Kjellen L, Lindahl U. Proteoglycans: structures and interactions. Annu Rev Biochem 1991;60:443-75.

5. Jackson RL, Busch SJ, Cardin AL. Glycosaminoglycans: molecular properties, protein interactions and role in physiological processes. Physiol Rev 1991;71:481-539.

6. Nakajima M, Irimura N, Ferrante DD, Ferrante ND, Nicolson GL. Heparan sulfate degradation: relation to tumor invasive and metastatic properties of mouse B16 melanoma sublines Science 1983;220:611-3.

7. Vlodavsky I, Fuks Z, Bar-Ner M, Ariav Y, Shirrmacher V. Lymphoma-cell-mediated degradation of sulfated proteoglycans in the sub-endothelial extracellular matrix: relationship to tumor-cell metastasis. Cancer Res 1983;43:2704-11.

8. Nakajima M, Irimura T, Nicolson GL. Heparanase and tumor metastasis. J Cell Biochem 1988;36:157-67.

9. Parish CR, Freeman C, Brown KJ, Francis DJ, Cowden WB. Identification of sulfate oligosaccharide-based inhibitors of tumor growth and metastasis using novel in vitro assays for angiogenesis and heparanase activity. Cancer Res 1999;59: 3433-41.

10. Vlodavsky I, Miao HQ, Benezra M, Lider O, Bar-Shavit R, Schmidt A, et al. Involvement of the extracellular matrix, heparan sulfate proteoglycans and heparan sulfate degrading enzymes in angiogenesis and metastasis. In: Lewis CE, Bicknell R, Ferrara N, editors. Tumor angiogenesis. Oxford: Oxford University Press; 1997. p. 125-40.
11. Vlodavsky I, Friedmann Y, Elkin M, Aingorn H, Atzmon R, Ishai-Michaeli R, et al. Mammalian heparanase: gene cloning, expression and function in tumor progression and metastasis. Nat Med 1999;5:793-802.

12. Hulett MD, Freeman C, Hamdorf BJ, Baker RT, Harris MJ, Parish CR. Cloning of mammalian heparanase, an important enzyme in tumor invasion and metastasis. Nat Med 1999;5: 803-9.

13. Toyoshima M, Nakajima M. Human heparanase, purification, characterization, cloning, and expression. J Biol Chem 1999;274:24153-60.

14. Kussie PH, Hulmes JD, Ludwig DL, Patal S, Navarro EC, Seddon AP, et al. Cloning and functional expression of a human heparanase gene. Biochem Biophys Res Commun 1999;261:183-7.

15. Japanese Gastric Cancer Association (editor). Japanese classification of gastric carcinoma. 13th ed. Tokyo: Kanehara; 1999.

16. Friedmann Y, Vlodavsky I, Aingorn H, Aviv A, Peretz T, Pecker I, et al. Expression of heparanase in normal, dysplastic, and neoplastic human colonic mucosa and stroma. Evidence for its role in colonic tumorigenesis. Am J Pathol 2000;157:1167-75.

17. Jing XF, Nakamura Y, Nakamura M, Yokoi T, Sha L, Taniguchi E, et al. Detection of Epstein-Barr virus DNA in gastric carcinoma with lymphoid stroma. Viral Immunol 1997;10: $49-58$.

18. Cox KH, Deleon DV, Anerer LM, Angerer RC. Detection of mRNAs in sea urchin embryos by in situ hybridization using asymmetric RNA probes. Dev Biol 1984;101:485-502.

19. Wight TN, Kinsella MG, Qwarntromn EE. The role of proteoglycans in cell adhesion, migration and proliferation. Curr Opin Cell Biol 1992;4:793-801.

20. Vlodavsky I, Eldor A, Haimovitz-Friedman A, Matzner Y, Ishai-Michaeli R, Lider O, et al. Expression of heparanase by platelets and circulating cells of the immune system: possible involvement in diapedesis and extravasation. Invasion Metastasis 1992;12:112-27.

21. Nakajima M, DeChavigny A, Johnson CE, Hamada JI, Stein CA, Nicolson GL. Suramin. A potent inhibitor of melanoma heparanase and invasion. J Biol Chem 1991;266:9661-6.

22. Freeman C, Parish CR. A rapid quantitative assay for the detection of mammalian heparanase activity. Biochem J 1997;325:229-37.

23. Nakajima M, Morikawa K, Fabra A, Bucana CD, Fidler IJ. Influence of organ environment on extracellular matrix degradative activity and metastasis of human colon carcinoma cells. J Natl Cancer Inst 1990;82:1890-8.

24. Nissen NN, Shankar R, Gamelli RL, Singh A, DiPietro LAI. Heparin and heparan sulphate protect basic fibroblast growth factor from non-enzymic glycosylation. Biochem J 1999;338:637-42.

25. Shiraishi N, Inomata M, Osawa N, Yasuda K, Adachi Y, Kitano S. Early and late recurrence after gastrectomy for gastric carcinoma, univariate and multivariate analysis. Cancer 2000;89:255-61.

26. Borie F, Millat B, Fingerhut A, Hay JM, Fagniez PL, Saxce BD. Lymphatic involvement in early gastric cancer, prevalence and prognosis in France. Arch Surg 2000;135:1218-23.

27. Inoue $\mathrm{H}$, Mimori $\mathrm{K}$, Utsunomiya $\mathrm{T}$, Sadanaga N, Barnard GF, Ueo $\mathrm{H}$, et al. Heparanase expression in clinical digestive malignancies. Oncol Rep 2001;8:539-42.

28. Bar-Ner M, Mayer M, Schirrmacher V, Vlodavsky I. Involvement of both heparanase and plasminogen activator in lymphoma cell-mediated degeneration of heparan sulfate in the subendothelial extracellular matrix. J Cell Biol 1986;128:299306. 